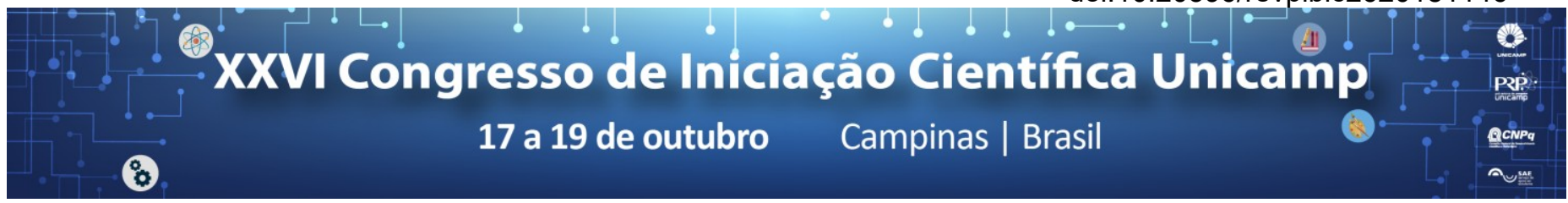

\title{
A relação da percepção social com o processo de expansão do mercado da energia solar fotovoltaica.
}

\section{Pedro Miguel de Melo Furigo*, Christiano França da Cunha.}

\section{Resumo}

Visto as crescentes exigências sociais e a necessidade inadiável de um desenvolvimento sustentável, a energia solar fotovoltaica apresenta-se como uma opção de investimento para a matriz elétrica brasileira, além disso, a regulamentação da geração distribuída permite que o cidadão comum também possa investir neste setor, desta forma, passa a ser fator chave na adoção desta tecnologia e na expansão do seu mercado consumidor. Este trabalho visou identificar como se dá na sociedade a percepção da energia solar fotovoltaica e de que forma a mesma tem influenciado na expansão desta tecnologia no mercado elétrico-energético brasileiro.

\section{Palavras-chave:}

Energia Solar Fotovoltaica, Percepção Social, Laddering.

\section{Introdução}

Segundo o IEA (2017), apenas $14 \%$ da produção energética mundial possui como fonte recursos renováveis, no Brasil, estes recursos representam $44 \%$ da matriz energética. Em relação à matriz elétrica, segundo DE FARIA et al (2017), a fonte hidráulica representa $65 \%$ da matriz nacional, fato que torna a mesma demasiadamente vulnerável à situações de baixa eficiência desta fonte, como, por exemplo, períodos de seca, outro ponto é que, apesar de ser renovável, a energia hidrelétrica apresenta diversos impactos socioambientais (BERMANN, 2012). Apesar disso, os impactos socioambientais desta tecnologia ainda são considerados menores em comparação com as demais fontes bases das matrizes internacionais, principalmente, quanto às fontes não-renováveis, desta forma, é necessário pensar a diversificação das fontes de geração elétrica, a energia solar fotovoltaica surge como opção neste contexto. A partir da resolução ANEEL 482/2012, surgiram novas possibilidades de expansão da energia solar fotovoltaica no mercado elétrico-energético brasileiro através da utilização de geração distribuída. Este trabalho visou identificar como a sociedade percebe a energia solar fotovoltaica e de que forma este fator influencia a expansão do seu mercado consumidor

\section{Resultados e Discussão}

Tabela 1: Índice de concordância das 120 entrevistas.

\begin{tabular}{|c|c|c|c|c|}
\hline Pergunta & $\begin{array}{l}\text { Inncice de } \\
\text { concerdisncis }\end{array}$ & 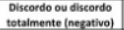 & 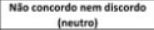 & 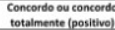 \\
\hline 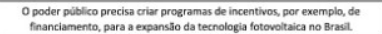 & 2.15 & s,00\% & $0,83 \mathrm{~K}$ & $94,17 \%$ \\
\hline 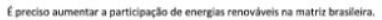 & 1.13 & 5,000 & $4.17 \mathrm{~K}$ & $90,83 \times$ \\
\hline 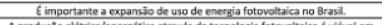 & 2,13 & $2,50 \%$ & $3,33 \times 3$ & $96,17 \%$ \\
\hline 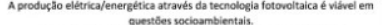 & 1.08 & 5,00\% & $4,17 \%$ & $90,83 \%$ \\
\hline 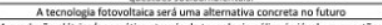 & 1,00 & $4,17 \pi \times$ & $9,177 \mathrm{x}$ & $86.67 \times$ \\
\hline 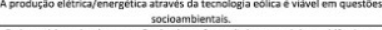 & 0.95 & 7,50\% & $5,833 \mathrm{x}$ & $86,67 \%$ \\
\hline 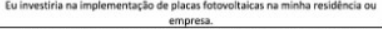 & 0,93 & $9,17 \%$ & $4,177 \mathrm{~K}$ & $86,67 \%$ \\
\hline 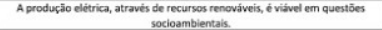 & 0,87 & $12,50 \mathrm{~K}$ & 5,00\% & $82.50 \%$ \\
\hline 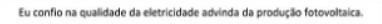 & 0,83 & $6.67 \mathrm{x}$ & 15,836 & n.sow \\
\hline 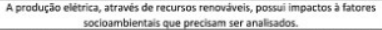 & 0,78 & $15,00 \%$ & 5,835 & $79,17 \%$ \\
\hline 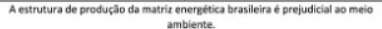 & 0.63 & 18,33\% & $9,17 \times$ & n.50\% \\
\hline 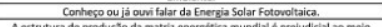 & 0,60 & $24,17 \%$ & $4,17 \times$ & $71,67 \%$ \\
\hline 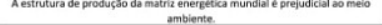 & 0.58 & $18,33 \mathrm{k}$ & $15,83 \mathrm{x}$ & $65,83 \%$ \\
\hline 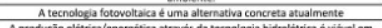 & 0,38 & $26,67 \times$ & $13,33 \mathrm{6}$ & 60,000 \\
\hline 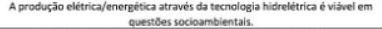 & 0.23 & $31,67 \%$ & $11,6 \%$ & $56,67 \%$ \\
\hline 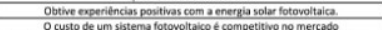 & 0.13 & $\frac{41,675}{40005}$ & $\frac{7,50 \times}{1750 \times}$ & $\frac{50.03 \times}{42509}$ \\
\hline 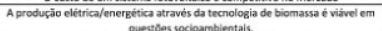 & $-0,03$ & $40,83 \mathrm{x}$ & 18,336 & $40,83 x$ \\
\hline 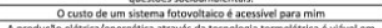 & $.0,22$ & $40,13 \times$ & 20,000 & $31.67 \%$ \\
\hline 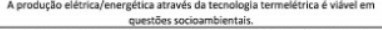 & $-0,42$ & $61,6 \% \mathrm{~K}$ & 13,336 & $25,00 \%$ \\
\hline 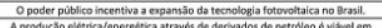 & $-0,43$ & $65,00 \%$ & $5,83 \times$ & $29,17 x$ \\
\hline 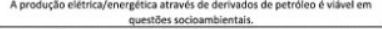 & .0 .57 & 70,000 & $6.67 \mathrm{~K}$ & 23,336 \\
\hline 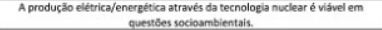 & -0.59 & $68,33 \mathrm{~K}$ & $14,17 \%$ & $17.50 \mathrm{~K}$ \\
\hline 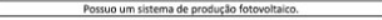 & 4.05 & $95,000 \mathrm{x}$ & $0.03 \mathrm{x}$ & $4,17 \times$ \\
\hline
\end{tabular}

Figura 1: Cadeia meio-fim da pesquisa.

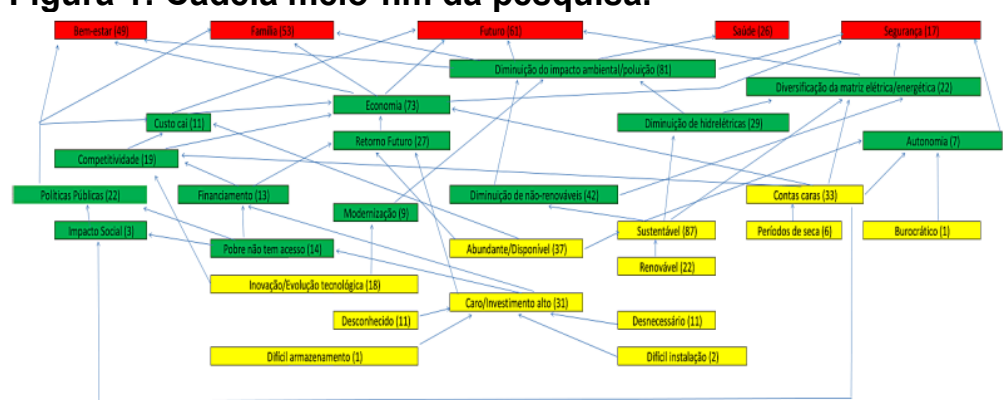

Fonte: Elaborado pelos autores.

Utilizou-se de um questionário estruturado em escala Likert e de um questionário semi-estruturado em laddering, realizou-se 120 entrevistas na cidade de Campinas, nas quais a amostra foi dividida em 4 regiões, classificadas conforme a composição socioeconômica de cada macrozona municipal (GUTMAN et al, 1988).

\section{Conclusões}

$72 \%$ da amostra responderam que conhecem ou que já ouviram falar da tecnologia. É possível dividir os resultados principais entre os fatores voltados à questão econômica e os voltados à questão socioambiental. Ela é percebida como uma tecnologia sustentável e que pode diminuir os impactos socioambientais, porém é considerada como um investimento alto e que, portanto, é inacessível às classes sociais menos abastadas, desta forma, é necessário investir em políticas públicas e/ou de financiamento para que haja uma expansão da sua adoção pelo mercado consumidor. Os principais valores percebidos se dão quanto à preocupação com o bemestar, com a família e com o futuro.

BERMANN, C. O projeto da Usina Hidrelétrica Belo Monte: a autocracia energética como paradigma. Novos Cadernos NAEA, v. 15, n. 1, 2012.

DE FARIA, $\mathrm{H}$ et al. Review of distributed generation with photovoltaic grid connected systems in Brazil: Challenges and prospects. 2017.

GUTMAN, J et al .Laddering theory, method, analysis, and interpretation. Journal of advertising research, 1988.

IEA - INTERNATIONAL ENERGY AGENCY. World energy balances. OECDiLibrary, 2017.

Fonte: Elaborado pelos autores. 